\title{
Poly (dimethyl siloxane) - organically modified montmorillonite based nanocomposites
}

\author{
Ancy Smitha Alex, Vijendra Kumar, Rajeev R.S., Supriya N, Manu S.K., Gouri C., \\ Bandyopadhyay G.G. and Sekkar V.* \\ Propellants, Polymers, Chemicals and Materials Entity, Vikram Sarabhai Space Centre, \\ Thiruvanathapuram-69522, India. \\ *Email: vsekkar@gmail.com
}

In the present study, we explore the scope of improvement on the properties of poly (dimethylsiloxane) (PDMS) through nanoclay incorporation. PDMS-organically modified clay (montmorillonite) nanocomposites were processed by the conventional technique of solution blending of nanoclay into the elastomer prior to cross-linking. The intercalation of the nanoclay was investigated through X-ray diffraction studies and it was observed that nanoclay is well exfoliated through intercalation of the polymer (Figure 1). The effect of nanoclay content on the mechanical, barrier, thermal and dynamic mechanical properties of the nanocomposites were investigated and compared with neat (non-reinforced) PDMS system. The mechanical properties of the PDMS improved substantially on reinforcement with nanoclay (Figure 2). The addition of nanoclay at $1 \%$ enhances the initial decomposition temperature (IDT) but subsequent increments of nanoclay reduces the IDT. Even though glass transition temperature remains practically same with increase in clay inclusion, Tan $\delta$ (max) decreases up to $2 \%$ and then shows upward trend with further nanoclay additions (Figure $3)$. This suggests that inclusion of nanoclay through small quantities may improve the damping characteristics of siloxane networks [1-3].

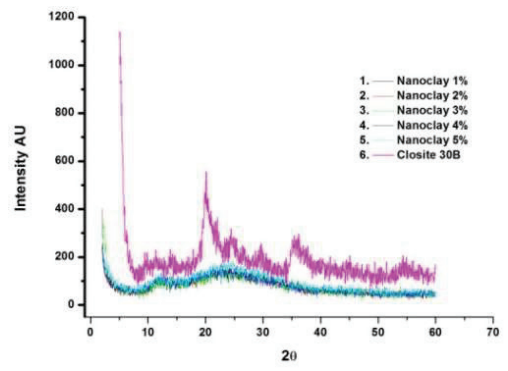

Figure 1: X-ray diffraction pattern of cloisite 30B and the PDMS- nanoclay composites

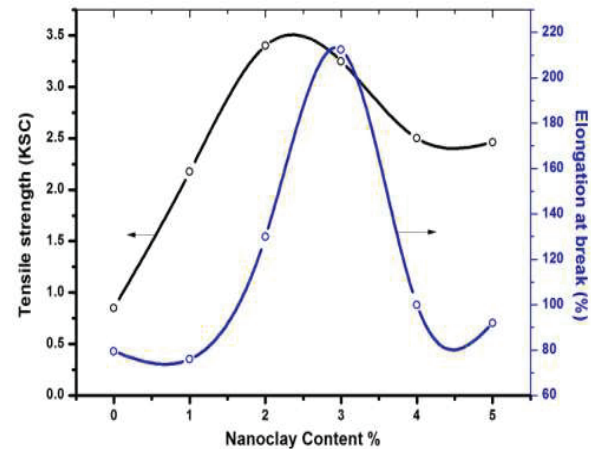

Figure 2: Variation of tensile strength and \% elongation at break of PDMS-nanoclay composites

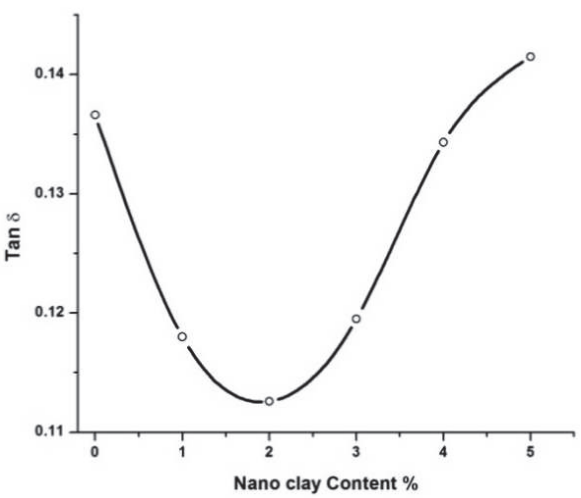

Figure 3: PDMS-Nanoclay composite - Tan $\delta(\max )$ vs. nanoclay content

\section{References}

1. Baron P C., Pinnavaia T. J., Chem. Mater., 13, 3760-3765(2001).

2. Pinnavaia, T. J. Science 1983, 220, 365.

3. Wang, Y. M. Organosil. Mater. Appl. Chin. 1992, 5,11 . 